\title{
PEMANFAATAN GAS METANA DARI LIMBAH CAIR SEBAGAI SUMBER ENERGI
}

\author{
Irhan Febijanto \\ Pusat Teknologi Pengembangan Sumberdaya Energi dan Industri Kimia- BPPT Gedung Energi 625 Klaster V, \\ Kawasan Puspiptek, Serpong-Tangerang Selatan 15314 \\ Email: irhan.febijanto@gmail.com
}

\begin{abstract}
Abstrak
Pemanfaatan biogas dari limbah cair Pabrik Kelapa Sawit (PKS) menjadi salah satu alternatif energi terbarukan yang berpotensi besar. Hal ini didukung dengan kondisi, bahwa negara Indonesia sebagai negara produksi minyak kelapa sawit terbesar di dunia, memiliki sekitar 700 PKS, milik swasta dan BUMN (Badan Usaha Milik Negara). PKS tersebar di pulau Sumatera, Kalimantan dan Sulawesi. Pemanfaatan biogas sebagai sumber energi listrik disambungkan ke grid PT PLN (Perusahaan Listrik Negara), merupakan usaha yang didukung pemerintah untuk meningkatkan rasio penggunaan energi terbarukan. Namun terjadi perubahan harga jual listrik berdasarkan Permen ESDM 12/2017, dimana harga jual listrik tidak lagi berdasarkan FIT (Feed in Tariff), namun berdasarkan Biaya Pokok Produksi (BPP) pembangkit di masing masing daerah. Perubahan harga jual ini, mengakibatkan menurunnya ketertarikan pengembang PLTBg. Untuk meningkatkan keekonomian, diperlukan optimasi penggunaan limbah kelapa sawit dengan cara meningkatkan pendapatan. Makalah ini bertujuan membahas potensi pemanfaatan biogas sebagai bahan bakar di boiler PKS untuk meningkatkan keekonomian PLTBg. Pengkajian dilakukan terhadap potensi biogas di salah satu PKS di propinsi Riau, dimana untuk meningkatkan keekonomian PLTBg, kelebihan biogas digunakan untuk menggantikan cangkang sebagai sumber bahan bakar boiler PKS. Cangkang yang digantikan dijual ke pasar, dan dari pendapatan penjualan cangkang, keekonomian PLTBg naik, dari IRR $=7,21 \%$, menjadi $14,43 \%$.
\end{abstract}

Kata-kata kunci: Pembangkit Listrik Tenaga Biogas, limbah cair, komponen harga, gas metana.

\begin{abstract}
Utilization of biogas generated from wastewater of Palm Oil Mills (POM) is one of the alternative renewable energy which has a huge potential. This potential is supported by about 700 of POMs owned by private companies or state own company which scattered in Sumatera, Kalimantan and Sulawesi, mainly. Utilization of biogas as an electricity contributes to increase ratio of renewable energy utilization. However, there is a change of selling electricity price according to Ministerial Decree of Energy and Mineral Resource of Republic of Indonesia No.:12/2017, which the price is not determined based on the FIT (Feed in Tariff) anymore. New price is based on Cost Production of Power Plant (BPP) and it leads to a decline in the economy rate of biogas power plant. Therefore, investors become uninterested for developing biogas power plant in the future. Potential additional revenue from selling palm kernel was studied. An excess biogas is used to substitute palm kernel shell as boiler fuel of POM, and the substituted shell is sold to the market. The additional revenue from selling the shell increased economy rate of the biogas power plant. It is shown that IRR=7,21\% increased to $14.43 \%$.
\end{abstract}

Keywords: Biogas Power Plant, wastewater, component price, methane gas. 


\section{PENDAHULUAN}

Pemanfaatan biogas sebagai hasil dari dekomposisi limbah cair dari hasil proses pembuatan minyak kelapa di pabrik kelapa sawit (PKS), mulai banyak dimanfaatkan saat adanya insentif karbon kredit sebagai tambahan pendapatan dari pemanfaatan biogas baik dalam bentuk flaring maupun penjualan listrik ke PT PLN. Karena pada waktu itu harga listrik untuk PLTBg masih jauh dari harga keekonomian, sehingga dibutuhkan pendapatan tambahan untuk menaikkan keekonomian seperti penjualan kredit karbon. Namun sekitar tahun 2014, harga karbon merosot tajam, sehingga tidak dapat lagi digunakan sebagai pendapatan tambahan yang dapat meningkatkan keekonomian proyek PLTBg. Pada tahun 2016 dikeluarkan Peraturan Menteri Energi Sumber Daya Mineral (ESDM) No. 21/2016, yang membuat para pengembang PLTBg tertarik untuk lebih mengembangkan PLTBg. Dengan Permen ini, harga jual listrik berdasarkan FIT (Feed in Tariff) ke PT PLN sangat menarik. Namun kondisi ini berubah dengan dikeluarkannya Permen ESDM No.12/2017, dimana harga jual listrik berubah menjadi berdasarkan BPP (Biaya Pokok Produksi), dan nilai keekonomian PLTBg menurun drastis [1].

Makalah ini mendiskusikan pemanfaatan biogas di PKS Trantam, Riau yang akan memanfaatkan biogas untuk pembangkit listrik namun mengalami penurunan keekonomian akibat berlakunya Permen ESDM No.12/2017. Dengan menghitung kebutuhan gas metana untuk sumber listrik, sisa gas metana digunakan untuk bahan bakar boiler di PKS untuk menggantikan sebagian bahan bakar boiler, yaitu cangkang. Dimana kelebihan cangkang dijual untuk menjadi pendapatan tambahan dari PLTBg, sehingga dapat menaikkan keekomomian PLTBg. Metodologi perhitungan gas metana menggunakan metodologi dari The United Nations Framework Convention on Climate Change (UNFCCC), AMSIII.H (Approved Methodology) (version 16):" Methane recovery in waste treatment" [2]. Parameter keekonomian digunakan IRR (Internal Rate of Return)

\section{Waktu dan Lokasi Penelitian}

Waktu Penelitian dilakukan antara bulan Juli 2016 dan November 2016. Lokasi penelitian diadakan di PKS Terantam yang berlokasi di Desa Kasikan, Kecamatan Tapung Hulu, Kabupaten Kampar, Propinsi Riau, dengan koordinat $100^{\circ} 45^{\prime} 02.8^{\prime \prime}$ N, $0^{\circ} 34^{\prime} 45.1^{\prime \prime}$. PKS ini berkapasitas 60 ton Tandan Buah Segar (TBS)/jam. PKS ini beroperasi dengan jam operasional rata-rata, 20 jam/hari dalam 285 hari/ tahun atau 5.700 jam/tahun (Kapasitas Faktor, $\mathrm{CF}=48 \%$ ).

\section{Bahan Bakar PKS Boiler}

Rasio limbah padat yang dihasilkan oleh PKS ditunjukkan pada gambar di bawah ini. Produksi cangkang kelapa sawit dan serabut berdasarkan material balance dari gambar di atas adalah $7 \%$ dan $13 \%$ terhadap jumlah TBS olah.

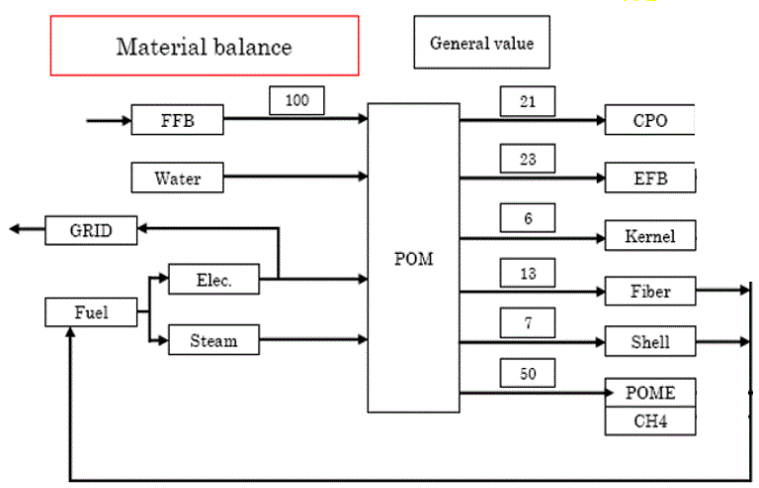

Gambar 1 Material Balance Limbah Padat dan Limbah Cair (NTT GP-ECO, 2009)

Maka dengan produsi rata-rata TBS dalam 4 tahun adalah $254.062 \mathrm{t}-\mathrm{TBS} / \mathrm{thn}$, maka produksi cangkang dan serabut masing-masing $19.562 .040 \mathrm{~kg} / \mathrm{thn}$ dan $32.768 .060 \mathrm{~kg} / \mathrm{thn}$. Seluruh serabut digunakan untuk bahan bakar PKS boiler, sedangkan cangkang sebagian dijual. Harga cangkang franco pabrik adalah Rp 500.000/ton [3]. 
Tabel 1 Spesifikasi Boiler

\begin{tabular}{|c|c|}
\hline \multicolumn{2}{|c|}{ Takuma N 600 SA } \\
\hline Boiler outlet & \\
\hline Tekanan uap air & $22 \mathrm{~kg} / \mathrm{cm}^{2}$ \\
\hline Laju uap air & $22 \mathrm{ton} / \mathrm{jam}$ \\
\hline Suhu uap air & $222^{\circ} \mathrm{C}$ \\
\hline Boiler inlet & \\
\hline Tekanan uap air & $0,11 \mathrm{~kg} / \mathrm{cm}^{2}$ \\
\hline Suhu feedwater & $47,8^{\circ} \mathrm{C}$ \\
\hline
\end{tabular}

Tabel 2 Pemakaian Energi Bahan Bakar

\begin{tabular}{|c|c|c|}
\hline Keterangan & Nilai & No \\
\hline Total energi 2-unit boiler & $534.120 \times 10^{6} \mathrm{~kJ} / \mathrm{thn}$ & 1 \\
\hline Suplai serabut & $32.768 .060 \mathrm{~kg} / \mathrm{thn}$ & 2 \\
\hline Nilai kalor & $11.326 \mathrm{~kJ} / \mathrm{kg}$ & 3 \\
\hline Energi dari serabut & $371.134 \times 10^{6} \mathrm{~kJ} / \mathrm{thn}$ & $4=2 \times 3$ \\
\hline Energi dari cangkang & $162.986 \times 10^{6} \mathrm{~kJ} / \mathrm{thn}$ & $5=1-4$ \\
\hline Nilai kalor cangkang & $23.374 \mathrm{~kJ} / \mathrm{kg}$ & 6 \\
\hline Suplai cangkang & $6.972 .991 \mathrm{~kg} / \mathrm{thn}$ & $7=5 / 6$ \\
\hline Sisa cangkang & $12.589 .049 \mathrm{~kg} / \mathrm{thn}$ & 8 \\
\hline
\end{tabular}

Pada PKS ini terdapat dua unit boiler dengan kapasitas pada boiler inlet dan outlet ditunjukan pada Tabel 1. Uap air yang diproduksi dari boiler, digunakan untuk menggerakkan generator dan untuk proses pengolahan minyak kelapa sawit. Dengan asumsi rasio uap air terhadap TBS adalah 650 $\mathrm{kg} / \mathrm{t}-\mathrm{TBS}$, dimana uap air dibutuhkan untuk proses pengolahan minyak kelapa sawit (sterilisasi, digester, pengeringan kernel dan proses lainnya) dan pembangkit listrik[4], maka total kebutuhan uap air untuk dua boiler adalah $39 \mathrm{t} / \mathrm{jam}$.

Dengan diketahui perbedaan enthalpi di boiler outlet dan boiler inlet serta effisiensi boiler $80 \%$, besar energi yang dibutuhkan untuk memproduksi uap air pada $\mathrm{P}=22 \mathrm{~kg} / \mathrm{cm}^{2}$ dan $\mathrm{T}=222^{\circ} \mathrm{C}$, sebanyak $39 \mathrm{t} / \mathrm{jam}$ adalah $35.285 \mathrm{~kJ} / \mathrm{s}$. Dengan kapasitas faktor $48 \%$ dalam setahun, maka kebutuhan energi yang dibangkitkan dari dua unit boiler dan energi yang disuplai dari bahan bakar cangkang dan serabut ditunjukkan di Tabel 2.

\section{Biogas dari POME}

Di sini akan Biogas yang dihasilkan dari limbah cair PKS (Palm Oil Mill Effluent), mengandung gas metana, $\mathrm{CH}_{4}$, sekitar 50-75\%, karbondioksida, $\mathrm{CO}_{2}, 25-45 \%$ dan gas lain sisanya. Biogas terjadi karena adanya proses dekomposisi zat-zat organik yang terjadi di kolam IPAL. Untuk mengetahui potensi gas metana dilakukan pengukuran COD dan jumlah POME dalam setahun.

Rasio POME/TBS digunakan untuk menentukan banyaknya POME yang dialirkan ke kolam IPAL. Dari beberapa referensi perhitungan rasio limbah cair terhadap TBS di PKS Sei Garo dan PKS Sei Galuh [5] serta PKS Sei Tandun dan PKS Sei Tapung [6], PKS Rokan dan PKS Terantam [7] menunjukkan angka rasio sebesar $0.7 \mathrm{~m}^{3} / \mathrm{t}$-TBS. Angka ini relatif tinggi dibandingkan dengan pengukuran di PKS lain yang menunjukkan angka $0.65 \mathrm{~m}^{3} / \mathrm{t}$-TBS [8] dan $0.67 \mathrm{~m}^{3} / \mathrm{t}-\mathrm{TBS}$ [9]. Pada studi ini, angka rasio POME/TBS adalah 0,7 ton.

\section{Besaran Biaya Pokok Penyediaan (BPP)}

Besaran Biaya Pokok Penyediaan (BPP) Pembangkit PT Perusahaan Listrik Negara (Persero) tahun 2016 diatur oleh Keputusan Menteri ESDM No: 1404 K/20/MEM/2017 tentang nilai BPP untuk tiap Propinsi. Nilai BPP untuk propinsi Riau adalah Rp 1.349/kW, maka maksimal harga jual adalah Rp $1.146,7 / \mathrm{kWh}$ (85\% dari BPP). Harga FIT sebelum BPP berlaku adalah Rp 1639,6/kWh.

Tabel 3 Parameter Keekonomian dan Operasional

\begin{tabular}{|c|c|}
\hline Masa perencanaan dan konstruksi & 1 thn \\
\hline Equity & $30 \%$ \\
\hline Biaya investasi & $\mathrm{Rp} 40,2 \mathrm{M}$ \\
\hline Suku bunga & $12,59 \%$ \\
\hline $\mathrm{CF}$ & $95 \%$ \\
\hline Jam operasi & $8760 \mathrm{jam}$ \\
\hline Masa manfaat & 20 thn \\
\hline Pemakaian Sendiri & $10 \%$ \\
\hline Komponen B+D & $5 \% \times \mathrm{A}$ \\
\hline Komponen C & Rp. 20/kWh \\
\hline Eskalasi B+D & $3,5 \% /$ thn \\
\hline Pajak Badan & $25 \%$ \\
\hline
\end{tabular}




\section{Asumsi Parameter Keekonomian}

Untuk asumsi keekonomian dan operasional ditunjukkan dalam tabel di bawah ini. Eskalasi komponen B dan D, diambil dari rata-rata nilai inflasi tahun 2016 [10]. Kurs USD terhadap Rupiah diasumsikan Rp.13.400/USD.

\section{Fasilitas Utama PLTBg}

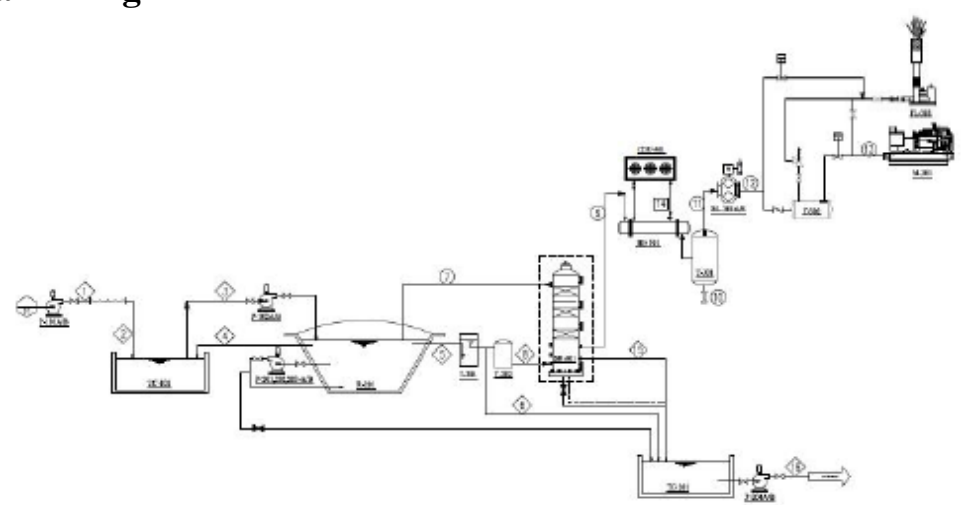

Gambar 2 Fasilitas Utama PLTBg dengan cover lagon

PLTBg ini dibangun dengan menggunakan teknologi CIGAR (Covered In-Ground Anaerobic Reactor) yang memakai cover lagoon yang ditutupi oleh HDPE (High-density polyethylene) sheet, untuk menangkap gas metana yang dihasilkan dari kolam anerobik-1. Gas metana yang ditangkap dialirkan ke scrubber dan dialirkan ke gas engine. Kelebihan produksi gas metana ditampung didalam reaktor. Untuk mengurangi tekanan sebagaian gas metana dibakar melalui peralatan flaring.

Secara umum proses produksi PLTBg ada 4 tahapan proses yaitu:
a) Feed Treatment
b) Biogas Reactor/Biodigester
c) Pemurnian biogas (gas handling Unit)
d) Gas Engine unit untuk produksi listrik

\section{Potensi Produksi Gas Metana}

Perhitungan emisi GRK dan potensi gas metana/ $\mathrm{CH}_{4}$ menggunakan metodologi dari The United Nations Framework Convention on Climate Change (UNFCCC), AMS-III.H (Approved Methodology) (version 16) : "Methane recovery in waste treatment" [2]. Perhitungan estimasi gas metana menggunakan hasil pengukuran COD dan rata-rata laju POME dalam setahun.

\section{Pengukuran COD, suhu dan pH}

Pengukuran dilakukan selama 3 hari berturut-turut pada saat PKS beroperasi. Dengan titik pengambilan outlet PKS, sebelum dan sesudah saluran pencampuran aliran dari kolam 1 dan dari kolam 4, kolam 1 anaerobik, kolam 2 anaerobik, dan kolam 3 anaerobik. Untuk pendinginan suhu limbah cair, aliran limbah cair sebelum masuk ke kolam 1 dicampur dengan aliran limbah dari kolam 4. Pengambilan sample dari kolam 1 dilakukan dekat outlet kolam 1.

Pengukuran COD dilakukan dengan menggunakan alat COD meter-Lovibond MD 100. Untuk hasil pembanding dilakukan pengukuran di Unit Pelaksana Teknis Pengujian Material, Dinas Bina marga, Riau di Pekanbaru. Pengukuran $\mathrm{pH}$ dilakukan dengan alat yang sama, COD meter-Lovibond $M D$ 100. Suhu limbah diukur dengan menggunakan thermometer air raksa, yang dimasukkan ke dalam air limbah.

Dalam perhitungan potensi gas metana hanya data COD yang diperlukan. Suhu dan $\mathrm{pH}$ digunakan untuk mendisain reaktor, agar sesuai dengan lingkungan bakteri mesofilik penghasil gas metana. Lingkungan yang sesuai untuk bakteri mesofilik adalah suhu $20-40^{\circ} \mathrm{C}$, optimum pada suhu $30-37^{\circ} \mathrm{C}$, dengan $\mathrm{pH}$ antara $6,6-7$. 


\section{Perhitungan Kapasitas Pembangkit}

Perhitungan kapasitas pembangkit memperhitungkan jumlah potensi gas metana yang ditangkap di kolam anaerobic. Dengan PLTBg kapasitas $1.025 \mathrm{~kW}$, efisiensi 38\%, merk SFGM 560 Guascor Biogas Engine. Listrik yang dihasilkan dialirkan ke jaringan tegangan menengah 20kV, selama 24 jam dalam 345 hari atau kapasitas faktor, $\mathrm{CF}=95 \%$.
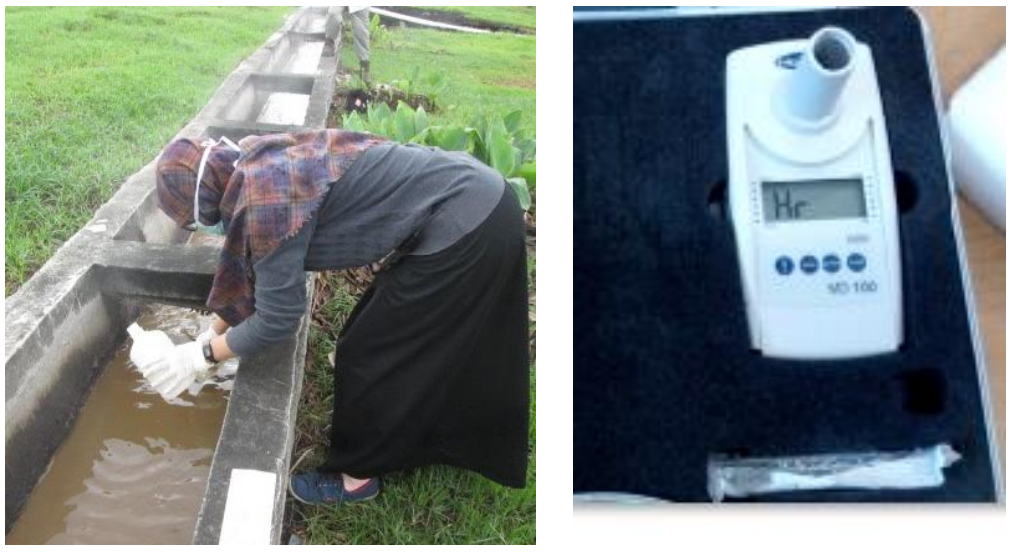

Gambar 3 Pengambilan Sample COD dan COD meter-Lovibond MD 100

\section{HASIL DAN PEMBAHASAN}

Hasil pengukuran COD pada inlet dan outlet kolam anerobik menunjukkan bahwa nilai rata-rata inlet kolam 1 (titik sample pada lokasi setelah pencampuran aliran dari outlet PKS dengan limbah cair dari kolam 4) dan outlet kolam 2 (titik sample outlet pada kolam 1) adalah masing masing $68.500 \mathrm{mg} / \mathrm{l}$ dan $18.050 \mathrm{mg} / \mathrm{l}$. Rasio reduksi COD pada kolam anaerobic 1 adalah $73.65 \%$. Nilai ini lebih hampir sama untuk pengukuran pada PKS milik PTPN, namun masih lebih rendah dari PKS milik swasta yang mencapai 90\% lebih[10], [11]. Ini dikarenakan perawatan, seperti kedalaman dan pembersihan kolam anaerobic milik perkebunan swasta lebih baik daripada perkebunan milik PTPN. Nilai COD ini relative tinggi dan sesuai dengan nilai COD di inlet kolam an-aerobik pada umumnya. Di kedua titik sample tersebut $\mathrm{pH}$ menunjukkan antara 6,45-7,5. Nilai $\mathrm{pH}$ ini masih berada pada interval optimal 7,0-8,0 untuk bakteri metanogen, dan $\mathrm{pH}$ optimum untuk proses mesofilik adalah 6,5-8,0. [12] [13].

Estimasi produksi metana dihitung dengan menggunakan metodologi dari The United Nations Framework Convention on Climate Change (UNFCCC), AMS-III.H (Approved Methodology) (version 16):" Methane recovery in waste treatment" [2]. Dari hasil perhitungan seperti ditunjukan pada Tabel 4.

Pada tabel 5, no 1 adalah nilai IRR saat harga jual listrik masih berdasarkan FIT, dimana keekomian sangat menarik para pengembang. Sejak Maret 2017, harga jual listrik berubah berdasarkan BPP masing - masing propinsi, dimana ini menurunkan keekomian proyek, menjadi $7,23 \%$.

Dengan kondisi menurunnya keekonomian proyek PLTBg ini, maka untuk menaikkan keekonomian, sisa gas metana digunakan untuk menggantikan sebagian cangkang bahan bakar boiler di PKS. Pada tabel 4 ditunjukkan, sisa gas metana $552 \mathrm{t}-\mathrm{CH}_{4} /$ thn digunakan untuk menggantikan sebagian jumlah cangkang di PKS boiler dengan nilai kalor yang sama, atau setara dengan cangkang seberat $1768 \mathrm{t} /$ thn. Dengan harga cangkang Rp 500.000/ton, didapat tambahan pendapatan sebesar Rp 884.244.460/thn.

Tambahan invesasi yang dibutuhkan adalah pengadaan pipa suplai gas $\mathrm{CH}_{4}$ ke boiler PKS menggunakan pipa hitam seamless 40 ' dengan panjang $500 \mathrm{~m}$ dari fasilias scrubber ke boiler, dengan 3 saluran, pompa penyuplai, dan burner. Investasi yang dibutuhkan sekitar $\mathrm{Rp} 2 \mathrm{M}$. Skema penggunaan gas metana ditunjukkan pada gambar di bawah ini, dimana selain ke biogas genset, gas metana juga dialirkan ke boiler dan ke flare. 
Tabel 4 Penggunaan Gas Metana, $\mathrm{CH}_{4}$

\begin{tabular}{ll}
\hline Gas Metana & $\mathbf{t}-\mathbf{C H}_{4} / \mathbf{t h n}$ \\
\hline Produksi gas metana & 2.010 \\
Digunakan untuk gas engine & 1.458 \\
Sisa gas metana & 552 \\
\hline
\end{tabular}

Tabel 5 Parameter Keekonomian

\begin{tabular}{|c|c|c|}
\hline \multirow[t]{2}{*}{1} & Harga Jual Listrik & \multirow{2}{*}{$\begin{array}{l}\text { Rp 1639,6/kWh } \\
31,27 \%\end{array}$} \\
\hline & IRR & \\
\hline & Pay Back Period & 3 thn \\
\hline 2 & Harga Jual Listrik & Rp 1.146,7/kWh \\
\hline & IRR & $7,23 \%$ \\
\hline & Pay Back Period & 11 thn \\
\hline
\end{tabular}

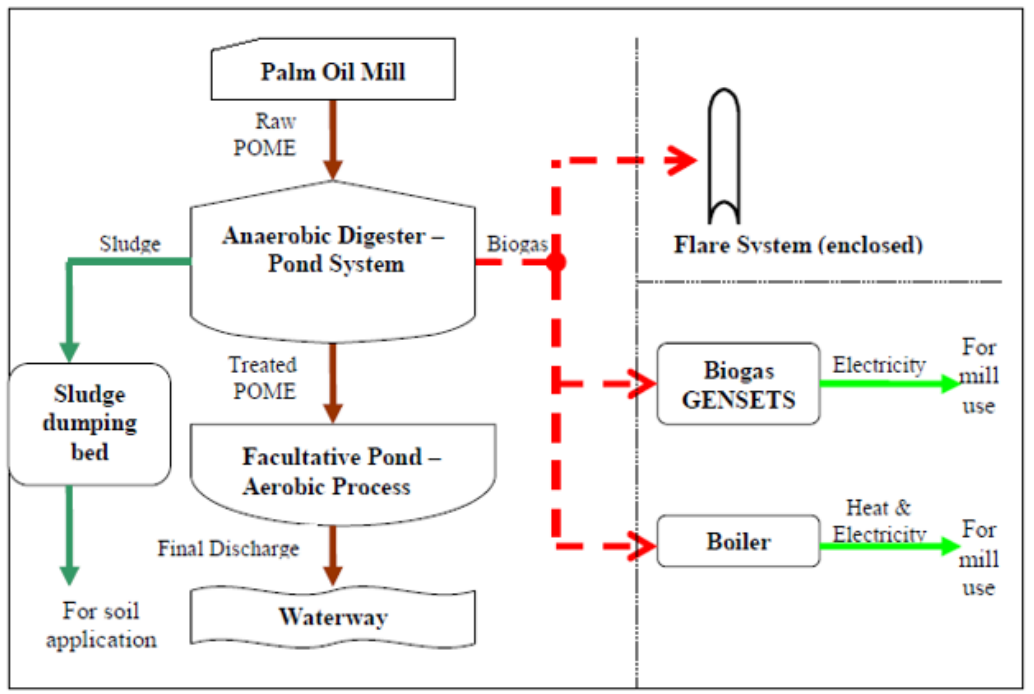

Gambar 4 Aliran Penggunaan Gas Metana

Dari tambahan pendapatan dan tambahan nilai investasi dengan asumsi keekonoian yang sama pada tabel 3, dilakukan perhitungan dengan hasil ditunjukkan pada tabel di bawah ini.

Pay back period cukup lama, namun mengingat usia pakai PLTBg sampai 20 thn, kondisi ini masih memungkinkan. Kapasitas faktor dari pabrik yang sangat rendah $48 \%$, menyebabkan produksi cangkang yang dapat digantikan oleh gas metana relatif sedikit, dan ini merupakan salah satu faktor lamanya pay back period.

Keekonomian proyek dapat lebih ditingkatkan dengan cara menurunkan nilai investasi, dengan meningkatkan komponen kandungan lokal dan peningkatan penguasaaan teknologi pembuatan komponen.

Peningkatan harga jual cangkang dengan cara menjual langsung tanpa melalui perantara lansung ke gudang penyimpanan pengumpul cangkang dapat meningkatkan nilai jual, namun perlu dipertimbangkan biaya transportasi.

Sampai saat ini di Indonesia diketahui baru satu proyek PLTBg yang menjual listrik ke PLN, umumnya penggunaan energi digunakan untuk kebutuhan sendiri maupun untuk suplai gas metana ke boiler. Mekanisme jual beli di lapangan yang terkadang tidak sesuai dengan aturan yang berlaku, aturan/ketentuan yang berubah-ubah, serta harga jual listrik yang rendah merupakan beberapa alasan dari pengembang untuk menunda atau tidak menyambungkan listrik ke PLN memalui mekanime Independent Power Producer (IPP). Umumnya sebagai excess power, listrik yang dibangkitkan dijual ke PT PLN. 
Tabel 6 Parameter Keekonomian

\begin{tabular}{llc}
\hline 1 & Harga Jual Listrik & $\mathrm{Rp} 1.146,7 / \mathrm{kWh}$ \\
\hline 2 & IRR & $14,43 \%$ \\
\hline 3 & Pay Back Period & $10 \mathrm{thn}$ \\
\hline
\end{tabular}

\section{SIMPULAN}

Dengan rendahnya harga jual listrik maka penggunaan gas metana sebagai bahan bakar pengganti cangkang merupakan salah satu alternative yang dapat dipertimbangkan untuk menaikkan keekonomian.

Peningkatan nilai kandungan komponen lokal, sangat diperlukan sebagai usaha untuk meningkatkan penguasaan teknologi dan keekonomian proyek PLTBg.

\section{REFERENSI}

[1] F. Irhan, "Tinjauan Komponen Harga Jual Tenaga Listrik dari Pembangkit Listrik Tenaga Biogas dengan Teknologi Cover Lagoon", in Prosiding Seminar Nasional Kimia UGM 2017, Meningkatkan Ketahanan Energi Nasional melalui Pengembangan Clean Energy, 13 Mei 2017, pp.86-90.

[2] UNFCCC, United Nations Framework Convention on Climate Change https://cdm.unfccc.int/Projects/projsearch.htm, (diakses 12 April 2017)

[3] Sihombing, A., and et. al., (2014), Analisis Perhitungan Ekonomi dan Potensi Penghematan Energi Listrik pada Pembangkit Listrik Tenaga Uap di Pabrik Kelapa Sawit PT. X, in Jurnal Energi Elektrik, Telekomunikasi \& Elektronika, 2(2). 2014, pp. 90-102.

[4] Nasrin, A.B and et.al, "Assessment of the Performance and Potential Export Renewable Energy (RE) from Typical Cogeneration Plants used in Palm Oil Mills", in Journal of Engineering and Applied Sciences, 6(6), 2011, pp. 433-439.

[5] PT KME (PT Karya Mas Energi), Biogas Bundled Project 2, ver. 12, 12/12/2012, https://cdm.unfccc.int/filestorage/h/n/RPK5SJ0BCO7FEHQ9IXAYL68WNG3V2Z.pdf/9233 -20121228-PDD.pdf?t=eFl8b25sZW5qfDDUeCshWhmew6EgRh6a3VSm. [Diakses 11 Januari 2017]

[6] PT KME (PT Karya Mas Energi), Biogas Bundled Project, ver.13.0, 16/11/2012, https://cdm.unfccc.int/filestorage/l/c/0XZT8K1WPODJFUIEV9MHSBQ5Y74CNA.pdf/8944 -\%20PDD-2012\%2012\%2020.pdf?t=dlR8b25sZXV1fDD5hwJiSvvAnIei6858Oiin. [Diakses 11 Januari 2017]

[7] PT KME (PT Karya Mas Energi), Biogas Bundled Project 3, ver. 12, https://cdm.unfccc.int/filestorage/3/n/JAO4FR9MLTEU3Z6BC8SXKQ5N2IDWVP.pdf/923 4-\%20PDD.pdf?t=T1R8b25sZXltfDCn8Hd1_5JsFbCQHdhvqF5A. [Diakses 15 Januari 2017]

[8] PT. KDA (PT Kresna Duta Agroindo), Methane recovery and electricity generation from POME at Pelakar Mill, Jambi, Indonesia, ver.3, 05/02/2013, https://cdm.unfccc.int/filestorage/a/n/FS5G08MC3JEU49WVKTAOXRPDZQB61H.pdf/703 1\%20PDD.pdf?t=VU58b25sZjN4fDBEYjTkyCgKQUCyefIoZFH6. [Diakses 15 Januari 2017]

[9] PT UL (PT Unggul Lestari), Methane Recovery and Utilisation at PT. Unggul Lestari Palm Oil Mill at Central Kalimantan, Indonesia. Ver. 09, 13/11/2012, https://cdm.unfccc.int/filestorage/b/p/DZF2W3RPE8OA60BT9XUJN5LYS741IV.pdf/6728 
\%20PDD\%2028\%20Nov\%2012.pdf?t=S0N8b25sZmVhfDBQyINV7p15uBID6FhKb1Xj,

[Diakses 10 Januari 2017]

[10] Bank Indonesia, Statistik Ekonomi dan Keuangan Indonesia (SEKI), Februari 2017

[11] Hayashi, K., (2007), "Environmental Impact of Palm Oil Industry in Indonesia", in Proceeding of International Symposium on Ecotopia Science, 2007, pp.646-651.

[12] Mahajoeno and et. al.," Potensi Limbah Cair Pabrik Minyak Kelapa Sawit untuk Produksi Biogas", in Jurnal Bioversitas, 2008, 9(1), pp. 48-52.

[13] Sosnowski, P., A, and et. al., "Anaerbobic co-digestion of sewage sludge and organic fraction of municipal solid wastes", in Adv, Environ Res, 2003. 7(3), pp. 609-616. 